\title{
AS POSSIBILIDADES DA EDUCAÇÃO NÃO FORMAL NOS MOOCS
}

\author{
LAS POSIBILIDADES DE LA EDUCACIÓN NO FORMAL EN LOS MOOC
}

\author{
THE POSSIBILITIES OF NON-FORMAL EDUCATION IN MOOCS
}

\author{
Jeong Cir Deborah ZADUSKI ${ }^{1}$ \\ Klaus SCHLÜNZEN JUNIOR ${ }^{2}$ \\ Danielle Aparecida do Nascimento dos SANTOS $^{3}$
}

RESUMO: Esse artigo expõe as possibilidades de aprendizagem em um ambiente não formal denominado Unesp Aberta, com cursos oferecidos no formato MOOC, em um espaço virtual aberto, gratuito e totalmente acessível, sem tutoria ou certificação, no qual a construção de conhecimentos é possível e observada a partir da interação entre cursistas. Para verificar a eficácia dessa hipótese, a pesquisa foi subdividida em três estudos: conhecer o perfil dos participantes nesses ambientes, identificando quem são e quais são suas necessidades; averiguar o grau de satisfação dos cursistas em relação ao curso, aos materiais propostos, às interações existentes e a sua percepção sobre a aprendizagem obtida e; identificar mecanismos de comunicação e interação entre aprendizes, tendo como base os fóruns de discussão e outros meios. A abordagem metodológica adotada foi a quanti-qualitativa, utilizando dois instrumentos: a observação não participante de três fóruns de discussão e um questionário semiestruturado enviado para todos os participantes dos cursos de ciências humanas. Foram analisados quantitativamente os 675 questionários considerados válidos, e, qualitativamente, com auxílio do software Iramuteq, as publicações feitas nos fóruns de discussão e as respostas dadas na pergunta aberta do questionário. $O$ estudo proporcionou a identificação do perfil dos aprendizes, a compreensão de suas percepções em relação aos recursos educacionais disponibilizados e à estrutura geral dos cursos. Além disso, foi possível afirmar que foram encontrados indícios de aprendizagem no ambiente de educação não formal analisado.

PALAVRAS-CHAVE: MOOCs. Educação Aberta. Aprendizagem ativa.

RESUMEN: Este trabajo aborda las posibilidades de aprendizaje en un entorno no formal denominado Unesp Aberta, en cursos ofrecidos en formato MOOC, en un espacio virtual abierto, libre y accesible, sin tutoría ni certificación donde la construcción de conocimiento sea posible y atestiguada a partir del Interacción entre

\footnotetext{
${ }^{1}$ Universidade Estadual Paulista (Unesp), Presidente Prudente - SP - Brasil. Doutoranda em Educação. E-mail: deborah_zaduski@hotmail.com.

${ }^{2}$ Universidade Estadual Paulista (Unesp), Presidente Prudente - SP - Brasil. Livre Docente em 'Aprendizagem Organizacional e Gestão de Conhecimento Corporativo: Um Estudo de Cenários para Explicitação de Conhecimento Tácito’.E-mail: klaus@fct.unesp.br. E-mail: romilda.ens@pucpr.br.

${ }^{3}$ Universidade Estadual Paulista (Unesp), Presidente Prudente - SP - Brasil. Professora Doutora do Programa de Pós-Graduação em Educação da Universidade do Oeste Paulista (UNOESTE). E-mail: danisantos.unesp@gmail.com
} 
los estudiantes. Para verificar la efectividad de esta hipótesis, la investigación se dividió en tres estudios. El primero fue conocer el perfil de los participantes en este entorno, identificando quiénes son y cuáles son sus necesidades. El segundo fue determinar el grado de satisfacción de los estudiantes con respecto al curso, los materiales propuestos, las interacciones existentes y su percepción sobre el aprendizaje obtenido. El tercero fue identificar mecanismos de comunicación e interacción entre aprendices, basados en foros de discusión y otros medios. El enfoque metodológico adoptado fue cuantitativo y cualitativo, utilizando dos instrumentos: la observación no participante de tres foros de discusión y un cuestionario semi-estructurado enviado a todos los participantes de los cursos de Ciencias Humanas. Se analizaron cuantitativamente los 675 cuestionarios considerados válidos y se analizaron cualitativamente las publicaciones realizadas en los foros de discusión y las respuestas dadas en la pregunta abierta del cuestionario con la ayuda del software Iramuteq. El estudio proporcionó la identificación del perfil de los alumnos, la comprensión de sus percepciones respecto a los recursos educativos disponibles y, en cuanto a la estructura general. Además, se pudo afirmar que se encontraron evidencias de aprendizaje en el entorno educativo no formal analizado.

PALABRAS CLAVE: MOOCs. Educación Abierta. Aprendizaje Activo.

ABSTRACT: This paper covers the possibilities of learning in a non-formal environment named Unesp Aberta, in courses offered in a MOOC format, in an open, free and accessible virtual space, without tutoring or certification where the construction of knowledge is possible and witnessed from the interaction between students. To verify the effectiveness of this hypothesis, the research was divided into three studies. The first was to know the profile of participants in this environment, identifying who they are and what are their needs. The second was to ascertain the degree of satisfaction of students regarding the course, the proposed materials, the existing interactions and their perception about the learning obtained. The third was to identify mechanisms of communication and interaction between apprentices, based on discussion forums and other means. Methodological approach adopted was quantitative and qualitative, using two instruments: the non-participant observation of three discussion forums and a semi-structured questionnaire sent to all participants of the Human Sciences courses. The 675 questionnaires considered valid were quantitatively analyzed and, the postings made in the discussion forums and the answers given in the open question of the questionnaire, were analyzed qualitatively with the help of the Iramuteq software. The study provided the identification of the learners' profile, the understanding of their perceptions regarding educational resources available and, regarding the general structure. In addition, it was possible to affirm that were found evidence of learning in the non-formal education environment analyzed.

KEYWORDS: MOOCs. Open Education. Active Learning.

\section{Introdução}


No mundo do trabalho é cada vez mais necessária a presença de profissionais com conhecimento vasto, especializado e dinâmico, e a exigência por diplomas e certificados logo será substituída pela necessidade de demonstrar habilidades e competências e a aplicação prática das teorias necessárias para o desempenho das profissões. Assim sendo, exigir que a aprendizagem seja decorrente exclusivamente de um processo formal de ensino, realizado em um período e espaço determinado e em conformidade com leis e normativas, significa diminuir as chances de avanço intelectual por parte dos profissionais, e o aumento da distância que separa países em desenvolvimento de países desenvolvidos, muitos dos quais já reconhecem os cursos realizados em plataformas livres e abertas como uma formação especializada válida e importante. Um exemplo é a plataforma Coursera, que anunciou em 2012 um trabalho de parceria com o Conselho Americano de Educação para iniciar uma avaliação de equivalência de crédito para alguns de seus cursos (COURSERA, 2013).

Em relação às práticas inovadoras e à aprendizagem facilitada pelo uso das tecnologias, encontramos muitos exemplos também no ensino híbrido e na educação presencial, como a experiência chamada "um buraco na parede" de Sugatra Mitra e a universidade 42, na França e nos Estados Unidos. Os exemplos são diferentes, os contextos e as realidades são diversas, mas o resultado é o mesmo: a aprendizagem ocorrendo fora dos processos tradicionais de ensino, em cenários que alguns considerariam como improváveis e, no entanto, são exemplos reais, que retratam o presente e o futuro da educação.

A experiência chamada "hole in the wall" (buraco na parede), idealizada por Sugata Mitra, chefe do Centro de Pesquisa em Sistemas Cognitivos do NIIT (National Indian Institute of Technology) instalou computadores em buracos feitos em paredes, permitindo que crianças pobres, sem nenhum acesso prévio a computadores e sem saber inglês, utilizassem o computador pela primeira vez. O experimento foi repetido diversas vezes e em várias partes da Índia, demonstrando que as crianças aprenderam sozinhas uma série de comandos necessários para utilizar recursos do computador, tais como jogos, baixar músicas, desenhar, entre outros, e ainda aprenderam muitas palavras em inglês, pois os softwares instalados nos computadores estavam em inglês. Segundo Mitra (2008), para que a aprendizagem aconteça não são necessários professores ou escolas tradicionais como as que ainda existem hoje. No caso das crianças da Índia, elas 
se auto-organizaram, ensinando e aprendendo umas com as outras, movidas pela curiosidade e pelo interesse legítimo em aprender.

Outro projeto inovador é a Universidade 42, uma instituição privada, sem fins lucrativos, aberta 24 horas por dia, sete dias por semana e, totalmente gratuita, que começou na França em 2013 e foi para os Estados Unidos em 2016. A metodologia de ensino utilizada no curso de programação de computadores se baseia na aprendizagem entre pares e na aprendizagem por projetos. Não existem professores e não são emitidos diplomas ou certificados ao término do curso. A duração do curso é flexível, varia de 3 a 5 anos, dependendo do ritmo e da motivação de cada um. Segundo Debise (2014), mais de 70.000 pessoas se inscreveram para as 875 vagas oferecidas na França e, apesar da ausência de diploma, os alunos saem com empregos garantidos em instituições como Google, Microsoft, Apple, Facebook e NASA.

O que essas experiências feitas em cenários e contextos tão diferentes têm em comum? O foco deixou de ser o ensino e passou a ser a aprendizagem. Não que o professor não seja mais necessário, pois por trás de todas essas experiências existem mentores, idealizadores, pessoas que acreditaram nessas ideias e que possibilitaram que elas acontecessem, fomentando atividades, interação, relacionamentos. Nestas experiências e ambientes, cujo foco é a aprendizagem, o cerne são os estudantes e a eles é dada a responsabilidade por sua auto-organização, fazendo com que quem sabe mais ensine quem sabe menos, em um processo de troca e colaboração, movendo-nos a avaliar com mais atenção o papel e a importância de ambientes informais e não-formais de educação.

\section{O Ambiente informal, não formal e formal de educação}

Para a compreensão do que está em questão neste artigo, é importante estabelecer uma relação conceitual, necessária para que não fiquem dúvidas sobre o tipo de aprendizagem elencado ao longo deste texto. Portanto, a aprendizagem formal é geralmente aquela obtida por meio de cursos ou aulas tradicionais, enquanto que a aprendizagem informal não segue essa estrutura, sendo fruto principalmente das interações feitas espontaneamente, socialmente e de forma não estruturada. Já a aprendizagem não formal é aquela que ocorre fora dos contextos de educação formal, 
geralmente extramuros escolares, principalmente como fruto da interação, da troca e do diálogo. Nas palavras de Gohn (2013, p.11)

A educação formal é aquela desenvolvida nas escolas, com conteúdos previamente demarcados; a informal como aquela que os indivíduos aprendem durante seu processo de socialização - na família, bairro, clube, amigos, etc., carregada de valores e cultura própria, de pertencimento e sentimentos herdados; e a educação não formal é aquela que se aprende "no mundo da vida", via os processos de compartilhamento de experiências, principalmente em espaços e ações coletivas cotidianas.

Assim, temos uma grande aproximação entre a fala da autora e os processos instaurados em espaços como os MOOCs, nos quais é forte a presença do compartilhar de experiências, reforçando a classificação destes espaços como fomentadores da educação não formal. Apesar da autora não fazer menção à educação a distância como um possível espaço de educação não formal, as características elencadas por Gohn (2013) relacionam-se com aquelas encontradas nesta pesquisa, ou seja, a organização voluntária das pessoas em um coletivo, visando a ressignificação de conceitos, a troca de experiências e a construção da identidade coletiva do grupo, afirmações que corroboram com o que dizem Palloff e Pratt (2007) sobre os cenários possíveis com a formação de comunidades de aprendizagem online.

Destarte, o intuito deste artigo é o de permitir uma compreensão melhor sobre as possibilidades de aprendizagem existentes em cenários de educação não-formal, na certeza de que atualmente a aprendizagem não é possível apenas nos sistemas tradicionais de ensino. É possível ensinar uns aos outros e aprender uns com os outros, tanto em ambientes presenciais ou de educação híbrida, quanto em ambientes virtuais, como é o caso da Unesp Aberta, objeto desse estudo e análise.

\section{A Unesp Aberta como universo de pesquisa}

O projeto de disponibilizar cursos on-line gratuitamente surgiu em 2012, como uma iniciativa da Reitoria da Universidade Estadual Paulista (Unesp) em conjunto com o seu Núcleo de Educação a Distância (NEaD). Os cursos oferecidos podem ser frequentados por qualquer pessoa, sem restrição de idade, grau de escolaridade e sem a necessidade de que o cursista possua formação prévia ou conhecimentos específicos, sendo o único requisito necessário a realização de um cadastro prévio na plataforma. Os cursos possuem formatos variados, tendo em comum a existência de um fórum no qual 
os participantes podem trocar informações de forma livre, respondendo os tópicos existentes ou criando tópicos novos, sobre o tema que desejarem. Outras características são a ausência de mediação pedagógica (tutoria) e a ausência de certificação e avaliação.

Em relação aos números, em 31 de agosto de 2016 a plataforma tinha um total de 200.608 usuários cadastrados em 70 cursos, sendo 1 de ciências biológicas, 9 de exatas e 60 de humanas. Em 23 de fevereiro de 2017 a plataforma já tinha 212.996 usuários, o que reitera a relevância e a significância desta plataforma. Além dos cursos também são disponibilizados gratuitamente e-books, separados por área de conhecimento, das quais 9 são de ciências biológicas, 13 de exatas e 170 de humanas.

A Unesp foi a primeira universidade no Brasil a lançar cursos no formato MOOC, sendo também pioneira na disponibilização de uma estrutura que possibilita que pessoas com qualquer tipo de deficiência acessem e participem dos cursos com autonomia. Apesar da ausência de tutores ou professores durante o curso, a estrutura, os materiais escritos, vídeos, textos complementares, e-books, artigos e demais recursos disponibilizados são cuidadosamente selecionados e analisados por professores especialistas da Unesp, sendo que muitos destes materiais são utilizados na própria Unesp em cursos regulares, acessíveis previamente somente para os alunos devidamente matriculados.

Dada a relevância e a quantidade significativa de usuários na plataforma, o questionamento a ser analisado são as possibilidades de aprendizagem, interação e satisfação para os aprendizes da sociedade digital que participam desses cursos. Para responder a pergunta, foi averiguada a disponibilização e o desenvolvimento de cursos em formato MOOC, em um ambiente de educação não formal on-line, procurando conhecer o perfil dos cursistas, o grau de satisfação deles em relação ao curso, os materiais propostos, às interações e à percepção pessoal sobre a aprendizagem, identificando mecanismos de comunicação e interação que registrassem indícios de aprendizagem nos diálogos encontrados.

\section{Procedimentos metodológicos e resultados}

Para a realização deste estudo foi adotada uma abordagem quanti-qualitativa. Quantitativa porque para compreender o perfil dos cursistas e verificar o grau de satisfação deles, foi enviado um questionário por e-mail para as 115.386 pessoas que se 
inscreveram nos 60 cursos de ciências humanas da Unesp Aberta, sendo que este instrumento continha nove perguntas fechadas e uma aberta. Os questionários foram acessados por 5421 pessoas, e respondidos por 833 , sendo que 158 tiveram que ser excluídos. Os 675 questionários considerados válidos foram analisados quantitativamente, observando estatisticamente as respostas que questionavam a percepção dos participantes em relação aos pilares: interação, aprendizagem e satisfação e; qualitativamente, comparando as respostas dadas nas perguntas fechadas com a opinião expressa livremente na última pergunta do questionário, aberta e não obrigatória. A análise foi feita com o auxílio do software Iramuteq, que permitiu o desenvolvimento de três estudos.

\section{Estudo 1}

No primeiro estudo buscou-se compreender quem são e o que pensam os participantes do ambiente Unesp Aberta dos cursos de ciências humanas, utilizando para tanto a mineração dos dados obtidos por meio do questionário. Do total de pessoas que responderam o questionário, $66 \%$ são mulheres e $34 \%$ são homens, confirmando as informações apontadas no Censo EaD 2014/2015, de que o público feminino é maioria nos cursos regulamentados totalmente a distância. Segundo as informações presentes no Censo, a maioria das instituições que respondeu essa questão declarou que mais da metade dos seus alunos era do sexo feminino. No tocante à média de idade dos cursistas que responderam ao questionário, é de aproximadamente 40 anos, configurando um público mais velho do que a média dos alunos que buscam os cursos universitários e grande parte dos cursos de especialização, refletindo na alta escolaridade encontrada entre os participantes.

Se comparada com a realidade presente nas grandes plataformas internacionais como a Coursera, são encontradas semelhanças. Nas palavras de Koller (2014), a maior parte dos estudantes que frequentam os MOOCs são pessoas em busca de uma formação específica sobre determinado assunto, trabalhadores que querem desenvolver uma habilidade específica por exigência do trabalho ou em busca de uma promoção, curiosos, ou pessoas de partes do mundo nas quais o acesso à universidade ainda é muito difícil, como por exemplo, na Índia, onde a oferta formativa não supre a demanda. 
No quesito escolaridade, a diferença nos percentuais é distinta, com mais de $90 \%$ dos entrevistados na graduação ou pós-graduação, e apenas $0,45 \%$ ou seja, 3 pessoas com ensino fundamental, apesar de terem 51, 40 e 25 anos. Faz-se importante destacar que a abrangência dos cursos oferecidos em relação à diversidade de participantes é muito grande, englobando uma variedade enorme de pessoas de diferentes idades e níveis formativos. A evidência também se faz presente nos depoimentos constantes na pergunta aberta, os quais reforçam os dados das perguntas fechadas, indicando a presença de professores que buscam complementar seus conhecimentos sobre temas específicos, alunos que gostariam de se matricular em cursos presenciais da Unesp, mas não conseguiram por morarem em cidades nas quais não existem polos presenciais ou por não terem conseguido passar no processo seletivo, pessoas de mais idade que afirmam que a educação a distância representa para elas a única possibilidade de acesso à universidade e tantos outros casos.

Observando a fala dos participantes que responderam à pergunta aberta do questionário, e as características do público-alvo dos cursos de ciências humanas da Unesp Aberta, encontramos um perfil diferenciado, formado por pessoas que, em muitos casos, demonstram estar prontas para um cenário de educação não formal, composto por um ambiente de aprendizagem com menos cobranças, menor apoio pedagógico, e mais possibilidades de interação livre, favorecendo o compartilhar de experiências, característica marcante deste tipo de ambiente educacional (GOHN, 2013).

Outra característica apontada por Gohn (2006) para a educação não-formal, que também está presente neste universo de pesquisa é a intencionalidade dos cursistas de participar de seu próprio aprendizado. Pois, tendo em vista a ausência de uma mediação pedagógica preestabelecida, é preciso que surjam, entre os cursistas, novos mediadores, pessoas capazes de responder as perguntas feitas e de fazer novas perguntas, em um processo de autorregulação, cujos atores são os próprios cursistas.

Como vimos, o perfil médio dos cursistas participantes desta pesquisa é composto por pessoas com idade média de 40 anos, o que representa maior maturidade emocional e autonomia, além do alto percentual médio de escolarização. Assim, os resultados obtidos apontam para um público-alvo preparado para compreender como funciona um curso no formato MOOC, o que reflete no alto grau de satisfação 
demonstrado pelos participantes nas respostas às perguntas fechadas do questionário, como veremos a seguir no estudo dois.

\section{Estudo 2}

No segundo estudo buscamos compreender se os três eixos que nortearam a construção do questionário, ou seja, satisfação, interação e aprendizagem estão correlacionados e, quais são os fatores que interferem na percepção do cursista em relação à satisfação. Para iniciar a exploração dos dados recolhidos começamos com o estudo das respostas referentes às três perguntas do eixo satisfação, a fim de ter uma visão geral da percepção dos cursistas que responderam ao questionário. Para tanto, as 675 respostas foram analisadas e os resultados apontam um nível geral positivo e satisfatório, tendo em vista que, no que se refere a esse eixo, as respostas foram todas acima de 3 pontos, o que é considerado positivo por se tratar de uma escala de 0 a 5 na qual o zero é sempre especificado como o mínimo (ou insatisfação), e cinco é o máximo (ou muito satisfeito).

É interessante notar a diferença da média da satisfação em relação ao curso e aos materiais, e a satisfação em relação às interações possibilitadas (ou não) durante o curso. Este resultado geral é diferente do resultado obtido quando são analisados separadamente os grupos etários, principalmente o grupo composto pelos participantes até 25 anos e acima de 55 anos. Por meio da análise dos dados fica claro que, apesar da maioria dos participantes estar satisfeita com o curso em linhas gerais, as opiniões não são uniformes, o que é normal e compreensível. Em um cenário ideal de aprendizagem, as necessidades formativas dos aprendizes devem ser ponderadas, levando em consideração o amadurecimento, as capacidades e as potencialidades de cada um, fazendo com que a aprendizagem seja mais eficaz, contextualizada e significativa (SCHLÜNZEN, 2015).

Os dados gerais da correlação entre satisfação e aprendizagem demonstram que $82 \%$ dos 675 cursistas afirmam estarem satisfeitos e terem aprendido o conteúdo proposto no curso. Apesar da opinião própria do entrevistado não ser o suficiente para determinar se houve de fato aprendizagem, considerando-se que não foram determinados os critérios avaliativos e os aprendentes não foram submetidos a nenhum tipo de avaliação, a opinião dos sujeitos não deve ser desconsiderada, pois eles são os 
principais conhecedores de si mesmos, de suas necessidades, em relação à aquisição de novos conhecimentos e ancoragem de novos conceitos (AUSUBEL, 1968).

Um dado curioso é que mesmo entre os entrevistados que alegaram insatisfação, o descontentamento não impediu a aprendizagem, o que reflete nas respostas que avaliaram com notas altas tanto a qualidade dos materiais quanto o curso, apesar dos participantes alegarem preferir cursos com tutoria. Por outro lado, 13\% dos cursistas alegaram satisfação sem aprendizagem, fato que está relacionado principalmente com a ausência da tutoria e/ou de ferramentas que possibilitem uma maior interação entre cursistas. Para estes cursistas, apesar da qualidade do curso e dos materiais disponibilizados influenciarem positivamente na satisfação, devido à ausência de interação e de diálogo, a aprendizagem não foi possível. Já para $4 \%$ dos cursistas, que alegaram insatisfação e falta de aprendizagem, tanto o formato quanto o conteúdo do curso não se adaptavam às suas necessidades.

Pela análise dos dados é notória a importância dada pelos participantes para a necessidade de que o curso tenha ferramentas que possibilitem o compartilhar de experiências, vivências e conhecimento entre os cursistas. Os resultados obtidos são muito coerentes com as pesquisas internacionais (KOLLER, 2014; PALLOFF, PRATT, 2007). Por exemplo, para os cursistas que se declararam insatisfeitos e sem aprendizagem, a interação é muito importante, mas as ferramentas existentes não possibilitaram essa troca, mesmo que um percentual um pouco acima da média acredite que estas interações significativas também possam ocorrer sem a presença de um tutor.

No outro extremo, para os que alegaram satisfação e aprendizagem, a maior diferença está exatamente na existência de ferramentas que possibilitaram a troca de experiências e o diálogo entre cursistas. Entre os dois níveis intermediários, ou seja, satisfeitos sem aprendizagem e insatisfeitos com aprendizagem, também fica clara a mesma correspondência direta com a existência das ferramentas que possibilitaram a interação, sendo que para o primeiro grupo o percentual é negativo e para o segundo é positivo, ou seja, mesmo estando insatisfeitos com o curso de modo geral, a aprendizagem foi possível, fato que tem ligação com as trocas possibilitadas e as ferramentas existentes.

Quando analisamos estatisticamente o percentual total de alunos entrevistados, podemos inferir que a qualidade, em geral, dos cursos oferecidos é muito boa e apresenta didática e design considerados bons, o que refletiu em um percentual de 
compreensão de conteúdo de 4,52, ou seja, bem próximo da nota máxima de 5 . Já em relação às possibilidades de contribuir com os pares e vice-versa, o percentual geral reflete a opinião da maioria, ou seja, dos $94.66 \%$ que se declararam satisfeitos com o curso realizado.

No entanto, um aspecto importante a ser notado é que para os $5.34 \%$ que se declararam insatisfeitos, a média de interação com os colegas foi muito pequena, o que não teve muita interferência na compreensão do conteúdo per se, mas na satisfação pessoal sim. Neste sentido, após a análise dos dados podemos inferir alguns aspectos iniciais:

$\checkmark \quad$ Em linhas gerais, pode-se afirmar que a maioria dos cursistas que respondeu ao questionário está satisfeita com o curso e afirma ter aprendido os conteúdos propostos, com a ressalva de que, por não ser obrigatório nem o curso, nem a pesquisa, esse fato pode significar que quem fez o curso e optou por responder a pesquisa são pessoas com predisposição para aprender on-line, em ambientes de aprendizagem não formais, ou pessoas que já estão familiarizadas com o ambiente de aprendizagem dos MOOCs.

$\checkmark \quad$ A satisfação em relação ao curso nem sempre significa aprendizagem. Algumas pessoas declararam que os conteúdos são ótimos e que foi possível a compreensão dos mesmos, contudo, para estas o formato do curso, ou a ausência da tutoria, ou a ausência de ferramentas que possibilitem uma maior interação, principalmente, foram fatores que influenciaram na ausência de aprendizagem.

$\checkmark \quad$ Existe uma relação direta entre a necessidade de trocar experiências e de dialogar com a aprendizagem, na opinião da maioria dos cursistas que responderam ao questionário, ou seja, quanto mais interação, mais aprendizagem.

$\checkmark \quad$ A insatisfação tem maior relação com a ausência de um tutor e com a necessidade de que sejam possibilitadas mais interações, do que com os conteúdos propostos.

E, para finalizar as analogias entre os eixos, a percepção individual em relação à aprendizagem varia de acordo com a faixa etária do participante, o que nos leva a concluir que a idade é um dos fatores que pode interferir na adaptabilidade do cursista para aprender em um ambiente virtual no qual são exigidos uma maior autonomia e compromisso pessoal para seguir a proposta do curso, tendo em vista que não existem tutores para estimular as interações e diálogos, confirmando o que foi relatado no primeiro estudo, onde foram abordados os aspectos relativos ao perfil dos participantes.

Ademais, pela análise dos dados podemos afirmar que, entre os entrevistados, o grupo mais satisfeito possui idade entre 36 e 45 anos, sendo que eles correspondem a 33\% dos entrevistados, ou seja, 223 pessoas. Entre os cursistas com idade média de até 25 anos (7\% do total de entrevistados) temos o maior percentual de pessoas que se declararam insatisfeitas, mas afirmaram ter aprendido os conteúdos propostos. Na outra 
ponta, entre os cursistas com idade média acima de 55 anos (10\% do total de entrevistados), temos o maior percentual de pessoas que alegaram satisfação em relação ao curso e aos materiais propostos sem, no entanto, terem conseguido aprender.

Outro dado a ser destacado é que nos grupos mais numerosos, ou seja, entre 26 e 35 anos e, entre 36 e 45 anos, os quais representam $24 \%$ e $33 \%$ do total de entrevistados, respectivamente, temos um percentual próximo a zero de cursistas insatisfeitos com aprendizagem, ou seja, quase ninguém afirmou ter aprendido, e ao mesmo tempo, estar descontente com o curso. Já o contrário, ou seja, pessoas que afirmaram não ter aprendido, mas gostaram da qualidade do curso e dos materiais, apresentou um índice flutuante entre $11,94 \%$ e 13,84\% em todos os grupos, exceto para os mais velhos, como citado anteriormente.

Assim sendo, em relação ao objetivo proposto para este segundo estudo, ou seja, o de verificar o grau de satisfação dos cursistas em relação ao curso, aos materiais propostos, às interações existentes e a percepção pessoal sobre a aprendizagem obtida no curso, pode-se afirmar que no geral, os cursistas estão satisfeitos, apesar das variáveis encontradas em relação à satisfação, ferramentas disponibilizadas, aprendizagem pessoal e possibilidades de aprendizagem entre pares.

\section{Estudo 3}

A proposta do terceiro estudo foi de identificar mecanismos de comunicação e interação entre aprendizes. Para tanto, foram selecionados 3 cursos, entre os 60 disponíveis, utilizando como critério de seleção os cursos nos quais as publicações feitas pelos cursistas foram maiores em quantidade e melhores em qualidade. Os aspectos observados visando identificar indícios de aprendizagem foram: troca de experiências sobre os temas propostos, o compartilhar de exemplos contextualizados e significativos dentro da realidade individual dos participantes, postagens que incitam o diálogo e a reflexão, respostas que sintetizam os assuntos abordados e/ou dialogam com as perguntas feitas pelos interlocutores.

\section{Curso 1: A lei de diretrizes e bases}

Curso com acessibilidade para pessoas com deficiências, com um total de 10.066 inscritos, avaliado com 4 estrelas por 328 pessoas e curtido no Facebook por 2,1 mil pessoas. O curso é dividido em quatro partes com leituras e atividades de fixação, além do fórum e de uma página com textos complementares. 
No café virtual, espaço no qual funciona o fórum, existem 128 postagens, sendo que o tópico com mais postagens é intitulado «Escolha democrática dos gestores escolares», e conta com 55 comentários. O cursista que abriu o tópico em 7 de março de 2013, o fez visando "discutir o critério de escolha dos gestores escolares". Nota-se que o intuito da postagem já é um convite ao diálogo tendo em vista que o cursista inicia dizendo "gostaria de discutir neste fórum" e, expõe qual a sua opinião sobre o tema. A sequência de mensagens aparece em uma linha de pensamento muito similar ao que encontramos em cursos formais oferecidos a distância, ou seja, alguns cursistas mencionam as mensagens anteriores, concordando ou discordando da linha de pensamento proposta, outros cursistas contextualizam o tópico com situações relacionadas ao seu dia-a-dia, outros ainda fazem novos questionamentos que confluem a partir do tema inicial, mas tratam de questões específicas ligadas à sua realidade.

Apesar da ausência de reciprocidade, no sentido de que quem fez o comentário muitas vezes não volta ao fórum para fazer uma nova postagem na resposta recebida, o que pode ser uma das consequências de uma oferta de curso de fluxo contínuo e longa duração, os cursistas subsequentes podem analisar toda a conversa antes de optar por responder ou não ao tópico, respondendo a algum tema específico, ou complementando o assunto com seu ponto de vista.

Vale recordar que, por se tratar de um fórum não obrigatório, considerando-se que não existe uma quantidade mínima de postagens necessárias, a motivação dos cursistas também é importante, e como não existe nota, ou pontuação extra, pode-se inferir que o propósito dos textos realmente seja a intenção de compartilhar, de refletir sobre o tema, de tornar público seus pensamentos em formato de texto, de modo claro e sistematizado. Essas características, como vimos em Gohn (2013), são típicas de um ambiente educacional não formal, ou seja, um espaço onde é possível partilhar, dialogar, aprender a viver juntos (DELORS, 1999).

Além disso, podemos encontrar já neste primeiro fórum alguns dos pressupostos que segundo Vygotsky (1974) caracterizam o processo de construção do conhecimento, tendo em vista os indícios apresentados de que os principais conceitos propostos pela disciplina foram interiorizados, e existe a busca pela interação porque os comentários não são feitos para serem avaliados, e sim em uma procura pelo compartilhar, expressa na leitura e concordância ou discordância dos pontos de vista, pois, em ambos os casos, o diálogo está presente. 
A figura apresentada a seguir, elaborada com o auxílio do software Iramuteq, reforça as ideias apresentadas.

RIAEE - Revista Ibero-Americana de Estudos em Educação, v.12 , n. esp. 2 , p. 1243-1266 , ago./2017. 
Figura 1: Análise gráfica do fórum Escolha democrática dos gestores escolares.

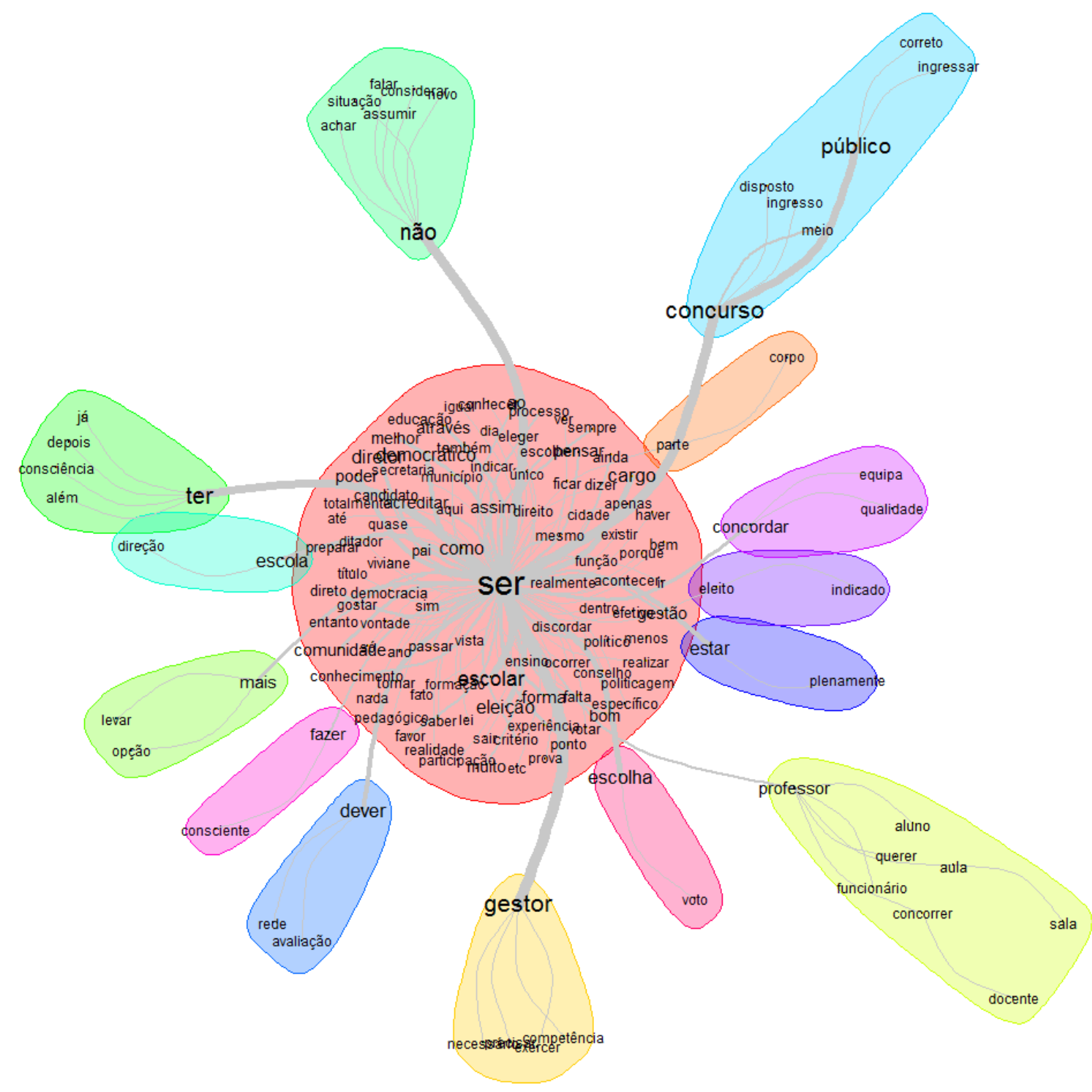

Fonte: Elaboração própria.

Observando a Figura 1, a centralização do verbo ser conflui para a ideia central de toda a discussão instaurada no fórum, tendo em vista que a opinião de cada cursista gira em torno de suas próprias experiências, do que cada um acredita ser a melhor alternativa para a escolha democrática dos novos gestores escolares. Os elementos encontrados contêm os pressupostos necessários para possibilitar a ocorrência da aprendizagem significativa, considerando-se que o diálogo fundamentado nas vivências individuais possibilita a ancoragem de novos conceitos ou sentidos aos que existiam previamente (AUSUBEL, 1968). 


\section{Curso 2: Filosofia da Linguagem}

O curso de filosofia da linguagem possui como ementa apresentar aos cursistas problemas filosóficos decorrentes de investigações sobre a natureza da linguagem. A estrutura é composta por um livro texto subdividido em quatro capítulos, 4 videoaulas correspondes a cada um dos capítulos do livro e uma videoaula extra. Além do fórum de discussões, o curso também disponibiliza 2 atividades auto corrigíveis para a fixação dos conteúdos propostos. A quantidade de inscritos, até 30/08/2016, data da recolha dos dados, foi de 1946 pessoas.

No fórum do curso foram criados 23 tópicos, e feitas 135 postagens de temas variados, na maioria dos casos estendendo os assuntos iniciados no livro texto e nas videoaulas, provocando o diálogo nestas temáticas ou em outras complementares.

Diferentemente do que aconteceu no curso sobre A Lei de Diretrizes e Bases, neste houve uma grande frequência de discursos longos, explorando não apenas as questões filosóficas, mas também curiosidades, vivências particulares e até mesmo gostos musicais, poesias, dicas de livros e textos que abordam outras questões ligadas à filosofia.

Por exemplo, no fórum intitulado "Perguntas e possíveis respostas", cujas 25 postagens renderam um total de 20 páginas de textos para análise, o clima do diálogo foi amigável e descontraído. como indicado no trecho, "Tenho costume de colocar uma música como pano de fundo da escrita, a de hoje foi Carlos Gardel cantada por Nelson Gonçalves", escrito por A.S, cuja resposta do colega R.S., ao final de sua longa postagem foi "Fundo musical: nenhum porque não consigo ouvir música e escrever a um só tempo; sou sempre exclusivo de um deles. Abraços fraternos".

Além das características típicas de um ambiente de aprendizagem não formal encontradas (GOHN, 2013), também estavam presentes elementos como o convite ao diálogo, o interesse em conhecer o outro, enxergar suas percepções e opiniões (MORAN, 2013); a aproximação entre os assuntos discutidos no fórum e os recursos disponibilizados no curso; o convite à reflexão.

Apesar das discussões serem muito ricas e fornecerem indícios de que foi instaurado um processo de aprendizagem fomentado pelas interações sociais entre os participantes (MATURANA, VARELA, 1995), pela construção coletiva do conhecimento (LÉVY, 2000) e pela formação de comunidades de aprendizagem 
(PALLOFF, PRATT, 2002), por questões práticas não reproduziremos aqui o fórum na íntegra, apresentando a seguir os principais elementos, por meio da nuvem de palavras elaborada com o auxílio do Iramuteq.

Figura 2: Nuvem de palavras do curso de Filosofia da Linguagem.

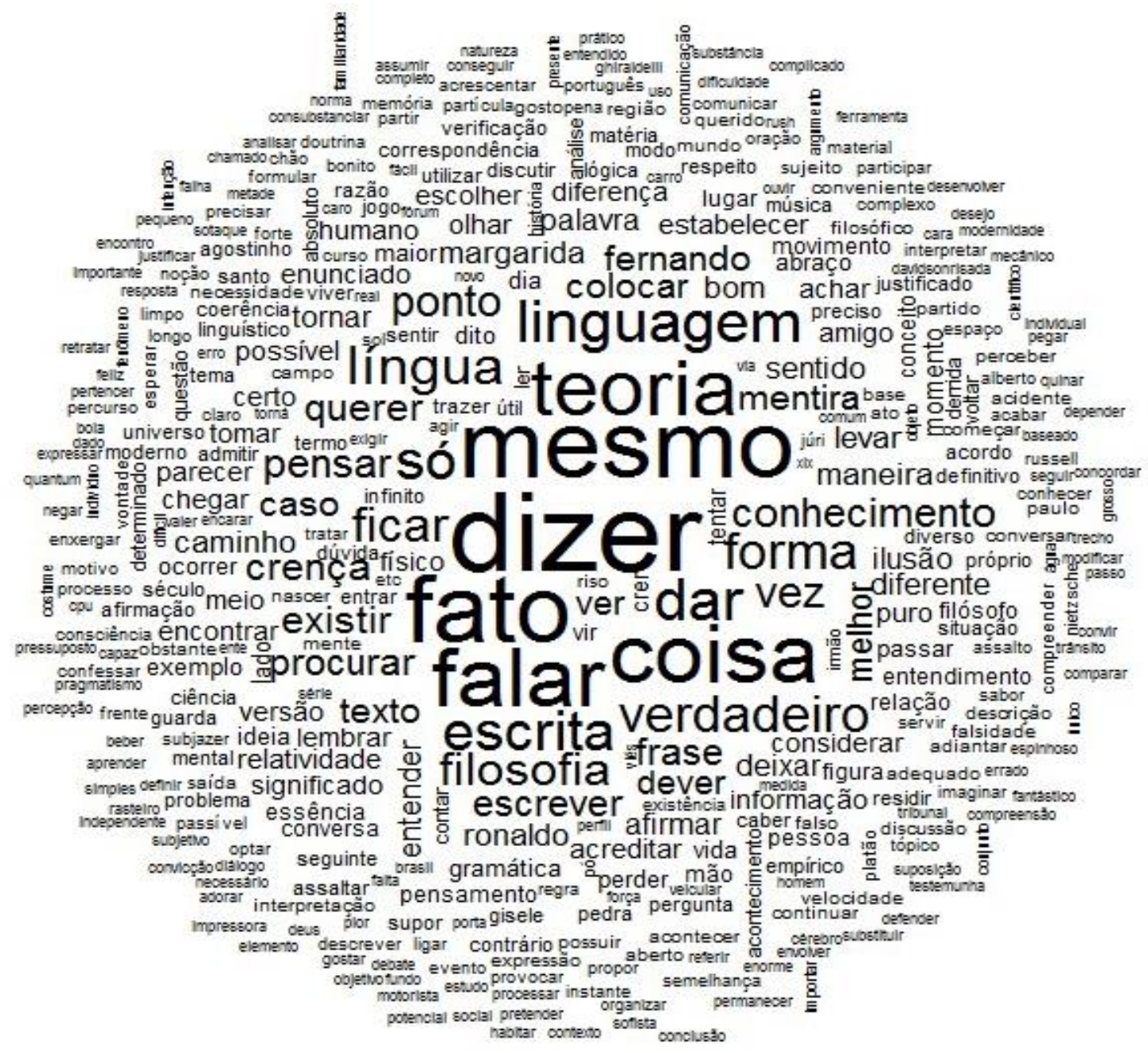

Fonte: Elaboração própria (ZADUSKI, 2017).

A Figura 2 representativa elenca claramente os elementos presentes nas postagens do fórum, ou seja, uma grande variedade de assuntos e temas, uma forte presença de verbos de ação, e a grande quantidade de postagens existentes, traduzidas em uma nuvem de palavras muito sortida e com muitos elementos.

\section{Curso 3: Ética}


O curso de ética tem como proposta tratar sobre problemas e discussões éticas da filosofia, abordando principalmente os conceitos éticos e filosóficos de Platão e Aristóteles e, ainda, discutir sobre o problema da conduta moral. O curso é um desmembramento da especialização em Filosofia, oferecido na modalidade a distância pela Unesp no projeto Redefor (Rede São Paulo de Formação Docente). A estrutura é similar aos já citados anteriormente, ou seja, livro texto com ficha do curso e 4 capítulos, videoaulas correspondentes ao material textual, uma videoaula extra, três atividades auto corrigíveis e o fórum de discussão. No que concerne à quantidade de pessoas cadastradas no curso, até 30/08/2016 o total foi de 2260 participantes.

O fórum deste curso, apesar de ser menor que os anteriores, apresentando um total de 13 tópicos e 24 postagens, também retratou os mesmos elementos que podem ser considerados como indícios de aprendizagem, tais como pensamentos encadeados, congruência nas postagens feitas, relação entre os recursos educacionais disponibilizados e os tópicos ou assuntos abordados, convite ao diálogo, partilha de ideias e opiniões, entre outros. Para complementar, a Figura 3 abaixo traz os elementos mais representativos presentes no diálogo estabelecido no tópico intitulado Ética e metafísica. 
Figura 3: Análise gráfica do curso de ética elaborada com o auxílio do software Iramuteq.

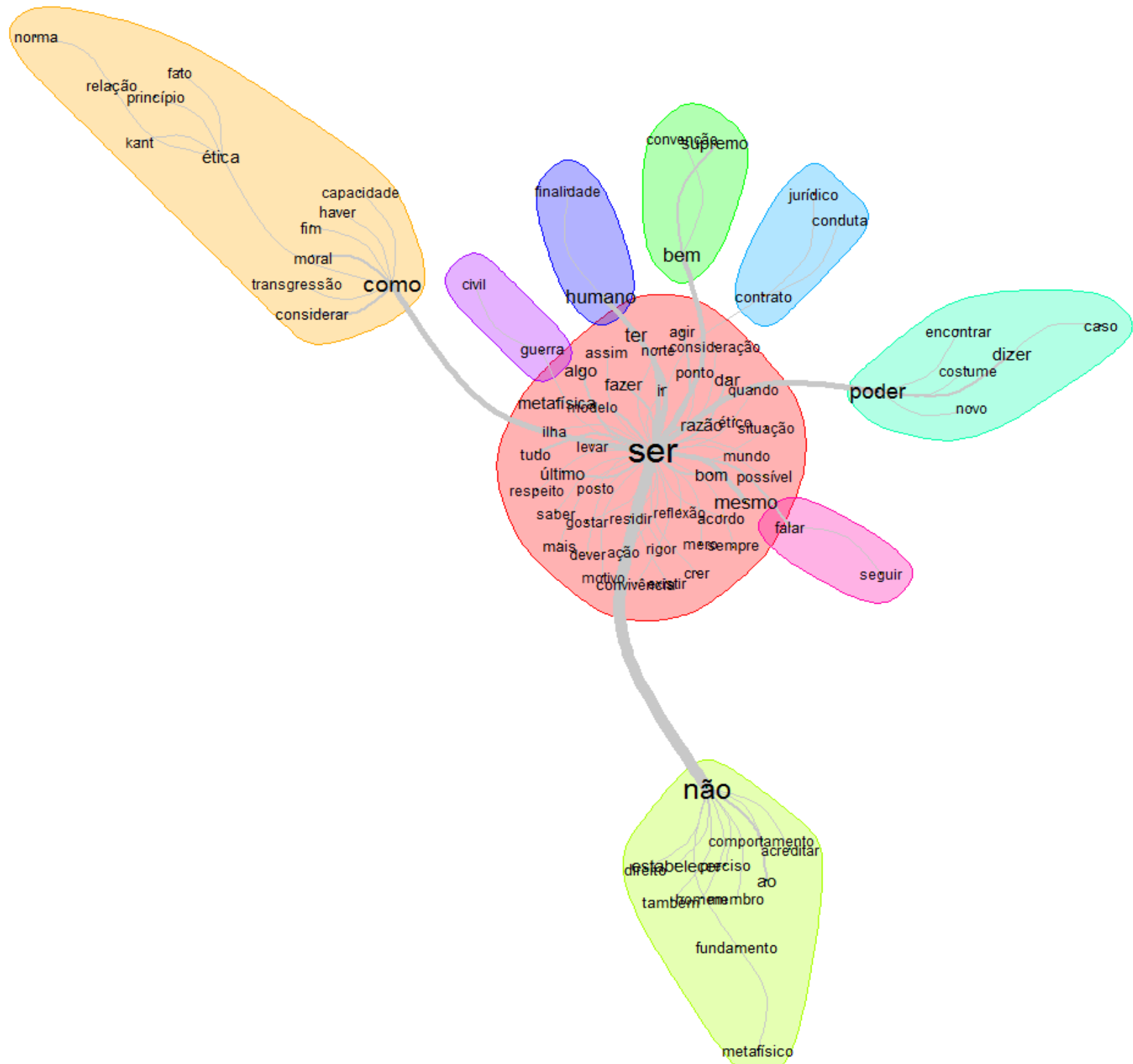

Fonte: Elaboração própria (ZADUSKI, 2017). 
Assim como demonstrado pelas análises anteriores, aqui também fica clara a fidedignidade da averiguação feita. Por exemplo, no caso deste tópico, a maior relação existente é entre o ser, e a sua negativa, ou o não, o que sintetiza o cerne do discurso presente neste tópico, ou seja, do que era ou não ético para os participantes, seguido em segundo plano, para a questão do como mantendo a mesma linha de raciocínio.

Finalizadas as análises que fizeram parte do terceiro estudo, podemos afirmar que foram identificados mecanismos de comunicação e interação entre os aprendizes dos cursos a lei de diretrizes e bases, filosofia da linguagem e ética. Além disso, foram identificados nos fóruns de discussão analisados elementos que denotam indícios de aprendizagem, em conformidade com os preceitos que alicerçaram esse estudo.

\section{Considerações finais}

Os resultados obtidos dos três estudos realizados validam as hipóteses iniciais de pesquisa, e indicam que o elemento mais importante em um curso no formato MOOC é a interação. No entanto, essa interação não precisa necessariamente ser com o tutor. Quando Valente nos fala sobre o Estar Junto Virtual (2003, p. 01) ele aponta "a necessidade da interação professor-aluno para que haja condição de construção de conhecimento". Os resultados relatados neste artigo mostram que é possível ampliar esse conceito. O Estar Junto Virtual é muito importante para a construção do conhecimento, porque somos seres comunitários (OLIVEIRA, 2013), estamos interligados ao meio no qual estamos inseridos (MATURANA, VARELA, 1995), e temos necessidade de pertencer a uma comunidade (MASLOW, 1943) porque compreendemos o mundo por meio do compartilhar de expectativas e vivências (HAGUETTE, 1992). Contudo, esse compartilhar de ideias, essa mediação, essa interação necessária para que a informação seja transformada em conhecimento, não precisa necessariamente da presença de um professor ou tutor. O que é completamente diferente de afirmar que o tutor ou professor é desnecessário. No cerne de todo processo formativo, na idealização de cursos (pequenos, médios ou massivos), na definição das atividades, no planejamento, em todos os detalhes a presença do professor é importante.

Mas o outro que tanto buscamos e necessitamos, àquele que pode nos auxiliar no nosso processo de construção do conhecimento, fazendo uma interação dentro da nossa Zona Proximal de Desenvolvimento (VYGOTSKY, 1974), pode ser um colega com um 
ponto de vista diferenciado, com um olhar diferente sobre uma mesma informação ou recurso. Por outro lado, é preciso sim estar junto, é preciso que os cursos sejam estruturados de modo a estimular esses momentos de interação para que eles sejam mais contextualizados e significativos (SCHLÜNZEN, 2015; AUSUBEL, 1968), fazendo com que pessoas com os mesmos interesses se encontrem virtualmente (ou presencialmente), otimizando suas experiências e potencializando a troca, o diálogo.

As comunidades de aprendizagem que se instauram dentro e fora de um MOOC não precisam estar restritas ao espaço virtual. As pessoas podem iniciar uma discussão em um café virtual e levá-la para uma cafeteria, para uma biblioteca, um restaurante. Uma das vantagens da educação não formal, comprovada pela observação realizada neste estudo, é que neste espaço é permitida uma comunicação mais descontraída entre os participantes, pois não existe a regra de que é preciso falar sobre um assunto predeterminado, não existe um mínimo de interações necessárias e, principalmente, ninguém será avaliado pelo que fizer ou deixar de fazer. Nesse espaço pode-se discutir filosofia ou poesia, música ou política, a interação é livre e só é necessária para quem tem o que dizer, e quer fazê-lo.

Como resultado do primeiro estudo realizado nesta pesquisa, foi confirmada a variedade enorme de pessoas que frequentam os cursos oferecidos no formato MOOC. Diferentemente dos cursos tradicionais de $\mathrm{EaD}$, cuja grande presença se concentra em pessoas que estão fazendo a graduação ou a pós-graduação, na Unesp Aberta encontramos um público que em média têm mais idade e já cursou a graduação ou a pós-graduação, buscando nos cursos algo mais específico ou mais imediato, um conteúdo trabalhado na graduação que não foi compreendido, uma complementação teórica, necessária no trabalho ou para desenvolver uma nova função, um hobby, uma curiosidade, uma necessidade, uma busca por novas experiências.

Como apontado no primeiro estudo, apesar de alguns resultados obtidos refletirem as informações provenientes de plataformas internacionais cuja abrangência em número de inscritos e oferta de cursos é muito maior (KOLLER, 2014), não podemos ter essas pesquisas como única referência, pois elas se fundamentam em outras realidades e contextos. A falta de pesquisas neste tema, principalmente em relação à contextualização do impacto trazido pelos MOOCs para a realidade social, cultural e política brasileira, faz com que exista uma lacuna a ser preenchida, dificultando nossa 
compreensão desta realidade e diminuindo nossas oportunidades de modificá-la conforme as necessidades educacionais do público brasileiro.

Em relação ao segundo estudo, os dados apontaram para uma percepção geral muito positiva dos cursistas que responderam os questionários enviados, os quais alegaram satisfação em relação aos materiais disponibilizados no ambiente virtual e ao curso em geral.

Um dado que chamou a atenção nesse estudo foi a importância dada às ferramentas necessárias para que a interação entre cursistas seja possível, demonstrando uma relação direta entre satisfação pessoal e a existência de ferramentas que possibilitem a interação. Entre os cursistas que alegaram insatisfação, muitos afirmaram que as ferramentas existentes não favoreceram para que a interação ocorresse. $O$ contrário também foi verdadeiro, ou seja, entre os que estavam satisfeitos, a afirmação é de que as ferramentas existentes possibilitaram a interação.

Claramente, e como era de se esperar, os resultados não foram uniformemente divididos em apenas duas linhas de pensamento, mas forneceram contribuições iniciais importantes para compreender como os cursos da plataforma e outros cursos no mesmo formato podem ser melhorados.

Por fim, com o terceiro estudo foi possível confirmar a riqueza de possibilidades de um ambiente virtual de aprendizagem aberto, online e livre, onde é concebível criar, compartilhar, aprender, ensinar, discutir o passado, o presente e o futuro. Também é permitido não discutir nada ou discutir somente o assunto trabalhado durante o curso. Nos MOOCs é possível que cada cursista aprenda somente o que tem interesse. Nada é obrigatório e cada um oferece e constrói na medida de suas próprias necessidades, percepções e vontades.

Se somos todos seres sociais porque criar cursos cujas interações são induzidas por notas e avaliações? Esse estudo nos mostra que é possível outro caminho. Se a estrutura existe, se as informações são interessantes, se o ambiente virtual contém estímulos que fomentem o diálogo, a interação também existirá e o processo de transformação da informação em conhecimento poderá acontecer, espontaneamente.

\section{REFERÊNCIAS}


AUSUBEL, David Paul. Educational psychology: a cognitive view. New York, Holt, Rinehart and Winston, 1968.

\section{COURSERA. American Council on Education to Evaluate Credit Equivalency for}

Coursera's Online Courses. 2012. Disponível em: < https://blog.coursera.org/american-council-on-education-to-evaluate-credit/> Acesso em: 07 abr. 2017.

COURSERA. Information about the platform, history and numbers. 2016. Disponível em <https://about.coursera.org/>. Acesso em: 30 out. 2016

DEBISE, Cécile. L'école 42: l'école du futur ? Disponível em: $<$ http://www.journaldunet.com/solutions/emploi-rh/reportage-a-l-ecole-42/uneselection-draconienne.shtml>. Acesso em: 15 jan. 2017.

DELORS, Jacques. Educação: um tesouro a descobrir. In: Relatório para a UNESCO da Comissão Internacional sobre educação para o século XXI. 2. ed. São Paulo: Cortez: Brasília-DF. MEC: UNESCO, 1999.

GOHN, Maria da Glória. Educação não-formal na pedagogia social.. In: I Congresso Internacional de Pedagogia Social, 1, 2006, . Proceedings online... Faculdade de Educação, Universidade de São Paulo, Disponível em: <http://www.proceedings.scielo.br/scielo.php?script=sci_arttext\&pid=MSC0000000092 006000100034\&lng=en\&nrm=abn>. Acesso em: 14 jan. 2017.

GOHN, Maria da Glória. Educação não formal: campos de atuação, de Ligia de Carvalho Abões Vercelli (Org.) Jundiaí: Paco, 2013.

HAGUETTE, Teresa Maria Frota. Metodologias qualitativas na sociologia. $3^{\text {a }}$ ed. Petrópolis: Vozes, 1992.

KOLLER, Daphne. Education, coursera and moocs. Interview with Russ Roberts at the Econtalk, 2014. Disponível em: <http://www.econtalk.org/archives/2014/08/daphne_koller_o.html>. Acesso em: 10 jul. 2016.

LÉVY, Pierre. A inteligência coletiva: por uma antropologia do ciberespaço. 3a edição. São Paulo: Edições Loyola, 2000.

MALHOTRA, Naresh K. Pesquisa de marketing: uma orientação aplicada. 3. ed. Porto Alegre: Bookman, 2001.

MASLOW, Abraham Harold. A preface to motivation theory. Psychosomatic Med., 1943, 5, 85-92.

MATURANA, R. Humberto.; VARELA, Francisco J. A árvore do conhecimento: as bases biológicas do entendimento humano. Campinas: Editorial Psy II, 1995.

MITRA, Sugata. O Furo na parede: sistemas auto-organizados em educação. $1^{\text {a }}$ edição. São Paulo: Editora Senac, 2008. 
MORAN, José Manoel. Educação que desejamos: novos desafios e como chegar lá. Livro eletrônico. Campinas, SP: Papirus, 2013.

OLIVEIRA, Clara Costa. O movimento da auto-organização e seus contributos para a educação. Revista Reflexão e Ação, Santa Cruz do Sul, v. 21, n. 2, p. 335-350, jul./dez. 2013. Disponível em: <http://online.unisc.br/seer/index.php/reflex>. Acesso em: 22 dez. 2016.

PALLOFF, Rena.; PRATT, Keith. Building online learning communities: Effective strategies for the virtual classroom. San Francisco: Jossey-Bass, 2007.

PALLOFF, Rena.; PRATT, Keith. Construindo comunidades de aprendizagem no ciberespaço: estratégias eficientes para a sala de aula on-line. Porto Alegre: Artmed, 2002.

RICHARDSON, Roberto Jarry. et al. Pesquisa Social: métodos e técnicas. São Paulo: Atlas, 1999.

SCHLÜNZEN, Elisa Tomoe Moriya. Abordagem construcionista, contextualizada e significativa: formação, extensão e pesquisa em uma perspectiva inclusiva. Tese de livre docência apresentada na disciplina Formação de Professores para uma Escola Digital e Inclusiva da Unesp. São Paulo, 2015.

TRIVINOS, Augusto Nibaldo Silva. Introdução a pesquisa em ciências sociais: a pesquisa qualitativa em educação. São Paulo (SP): Atlas, 1994.

VALENTE, José Armando. Blended Learning e as mudanças no ensino superior: a proposta da sala de aula invertida. Educar em Revista (Impresso), v. Especial 4, p. 7997, 2014.

VYGOTSKY, Lev Semyonovich. Storia dello sviluppo delle funzioni psichiche superiori. Firenze: Giunti Barbera, 1974.

ZADUSKI, Jeong Cir Deborah .; SCHLÜNZEN JUNIOR, Klaus.; SANTOS, Danielle Aparecida do Nascimento dos. As possibilidades da educação não formal nos MOOCs. Revista Ibero-Americana de Estudos em Educação, Araraquara, v. 12, n. esp. 2, p. 1243-1266, ago./2017. Disponível em: <http://dx.doi.org/10.21723/riaee.v12.n.esp.2.10293>. E-ISSN: 1982-5587.

Submetido em: 10/05/2017

Aprovado em: 28/07/2017 